\title{
Standardisation and development of antioxidant rich food: Product using broccoli and mushroom
}

\author{
Mamta Jaiswal and Neelam Yadav
}

The objective of present investigation on standardisation and development of antioxidant rich food: Product using broccoli and mushroom was to standardize and develop the products using broccoli and mushroom and their organoleptic evaluation. Antioxidant are naturally occurring substances that combat oxidative damage in biological entitives. An antioxidant achieves this by slowing or preventing the oxidation process that can damage cells in the body. This it does by getting oxidized itself in place of the cells. Thus, an antioxidant can also be termed as a reducing agent. Antioxidant are considered as important in the fight against the damage that can be done by free radicals produced due to oxidative stress. Although the human body has its own defenese against oxidative stress, these become weak with age or in the case of an illness. Developed products of broccoli and mushroom were broccoli mushroom soup and broccoli and mushroom curry. The organoleptic evaluation of products was done by using (9-Point Hedonic Scale). The result of broccoli and mushroom based products for broccoli mushroom soup, broccoli and mushroom curry $\left(\mathrm{T}_{1}\right)$ were best in all treatments in case of all sensory attributes. The overall acceptability of experimental $\left(\mathrm{T}_{1}\right)$ broccoli mushroom soup and broccoli and mushroom curry were 8 and 8.2, respectively. Developed products were accepted by panel members.

Key Words : Antioxidant, Organoleptic evaluations, Developed, Treatments

How to cite this article : Jaiswal, Mamta and Yadav, Neelam (2018). Standardisation and development of antioxidant rich food: Product using broccoli and mushroom. Food Sci. Res. J., 9(2): 250-253, DOI : 10.15740/HAS/FSRJ/9.2/250-253. Copyright@ 2018: Hind Agri-Horticultural Society. 